\title{
Decline in the lung cancer hazard: a prospective study of the mortality of iron ore miners in Cumbria
}

\author{
L J KINLEN,' A N WILLOWS
}

From the CRC Cancer Epidemiology Unit, 'University of Edinburgh, Edinburgh EH8 9JZ, and the CRC Cancer Epidemiology Research Group, ${ }^{2}$ Department of Community Medicine and General Practice, The Radcliffe Infirmary, Oxford, UK

ABSTRACT The mortality of 1947 Cumbrian iron ore miners has been studied over the period 193982 in relation to that among other groups of men in England and Wales: (a) all men, (b) men of similar social class, and (c) men living in similar types of (mainly rural) area. Significant excesses were found for deaths from tuberculosis and respiratory diseases compared with each of the reference populations. Lung cancer showed an excess over that in comparable (mainly rural) areas of England and Wales, as reported in a previous study using a proportionate method of analysis and which covered the period 1948-67 but no appreciable excess after 1967. Reasons for this decline are discussed.

Iron ore miners in Cumbria have been found to have a significantly increased mortality from lung cancer, an effect attributed either to the radioactivity in the underground air or to a carcinogenic effect of iron oxide. $^{1}$ In that study it was not possible to obtain adequate details of the population exposed and consequently the mortality data were analysed using a proportionate method. It was considered that a prospective study would be of interest, since this would allow not only a comparison of the findings with those of the previous study but also an examination of mortality from causes not covered previously. Such a study has now been carried out using data held in the National Health Service Central Register (NHSCR) for England and Wales.

\section{Methods}

Details were abstracted from the NHSCR by staff of the Office of Population Censuses and Surveys (OPCS) of men resident in September 1939 in Ennerdale RD and Whitehaven UD, Cumberland, and whose occupation as stated included a mention of "iron ore mine"; those described as retired were also covered. In addition to the job description as given the details abstracted included dates of birth and, when relevant, dates of death or emigration.

In the case of deaths details of the underlying cause

Accepted 6 April 1987 were obtained from the death certificates and coded by the OPCS according to the rules of the 8th revision of the International Classification of Diseases (ICD). In many cases the men were specifically described as "surface" or "underground" workers and the data for these categories have been analysed separately, as has also a third group comprising those in which neither term was mentioned. In a few cases when there could be no doubt about the matter a worker was allocated to one of the first two categories even though the words underground or surface did not appear-for example, "shopfirer" or "clerk in the iron mine".

For each work category and for each area of residence in 1939 (Ennerdale RD and Whitehaven MB), man-years at risk by age group and calendar period were calculated for 1939-83. Expected numbers of deaths attributed to particular causes were obtained by multiplying the man-years at risk in each area, age group, and calendar period by the corresponding mortality rates for the following: (1) all men in England and Wales, (2) men in all rural districts (for comparison with men in Ennerdale RD) and in all urban areas with populations over 50000 (for the Whitehaven MB residents), and (3) for men in social classes III and IV combined. For 1939-49 and 1973-82 death rates for urban and rural areas were not published separately and were derived by applying the age specific ratios that related national to urban and also to rural rates in $1950-57$ and $1968-72$ to the corresponding national rates in 1939-49 and 1973-82 respectively. Appropriate rates were derived from 
published annual figures by conversion of all ICD codes to 8th revision equivalents. Social class specific mortality data are available only for (a) 1949-53, (b) 1959-63, and (c) 1970-2. The factors that related national rates to the combined rates for social classes III and IV for each of these three periods were used to derive rates for classes III and IV for the remaining periods (a) 1940-8 and 1954 (b) 1955-8 and 1964, and $(c) \quad 1965-9$ and $1973-82$. All the analyses by social class were restricted to men below age 65 , since relevant mortality data are not available above this age.

In addition, the mortality data were also analysed by the proportionate method used by Boyd and his colleagues. 'As in the previous study this was restricted to men whose death certificates indicated that they had been iron mine workers. For this purpose, ratios were calculated for each age group and calendar period, from published mortality data for all rural districts of England and Wales of the numbers of deaths from lung cancer, other cancers, and respiratory diseases to the numbers of deaths in each age group and calendar period from all other causes. A similar procedure was applied to data for all urban areas with populations under 50000 of England and Wales. These two sets of ratios were then applied to the corresponding numbers of deaths from causes other than cancer and respiratory disease that occurred among the study population in Ennerdale RD and Whitehaven UD to yield expected numbers of deaths from lung cancer, other cancers, and respiratory diseases in the study population.

\section{Results}

MAN-YEARS ANALYSIS

Details were found in the NHSCR of 1947 men resident in 1939 in Ennerdale RD or Whitehaven UD aged under 85 and described as active or retired iron mine workers. Their numbers are shown in table 1 according to age group and occupational category: $95 \%$ of the men lived in Ennerdale RD and $5 \%$ in

Table 1 Numbers of iron mine workers by occupational category and age group

\begin{tabular}{|c|c|c|c|c|}
\hline Age & Above ground & Below ground & Not specified & Total \\
\hline $\begin{array}{l}15-24 \\
25-34 \\
35-44 \\
45-54 \\
55-64 \\
65-74 \\
75-84\end{array}$ & $\begin{array}{r}16 \\
18 \\
19 \\
25 \\
24 \\
7 \\
1\end{array}$ & $\begin{array}{r}45 \\
136 \\
190 \\
205 \\
180 \\
87 \\
21\end{array}$ & $\begin{array}{r}112 \\
218 \\
203 \\
194 \\
152 \\
81 \\
13\end{array}$ & $\begin{array}{r}173 \\
372 \\
412 \\
424 \\
356 \\
175 \\
35\end{array}$ \\
\hline Total & 110 & 864 & 973 & 1947 \\
\hline
\end{tabular}

The numbers resident in Ennerdale RD were 1859, of which 85 worked above ground, 845 below ground, and 929 were not specified.
Table 2 Man-years at risk by age group and occupational category

\begin{tabular}{lcccc}
\hline Age & Above ground & Below ground & Not specified & Total \\
\hline $15-24$ & 73 & 142 & 405 & 620 \\
$25-34$ & 238 & 888 & 1989 & 3115 \\
$35-44$ & 439 & 2415 & 4081 & 6935 \\
$45-54$ & 587 & 3942 & 5743 & 10272 \\
$55-64$ & 713 & 4816 & 6531 & 12059 \\
$65-74$ & 496 & 3680 & 4796 & 8972 \\
$75-84$ & 232 & 1273 & 1714 & 3219 \\
Total & 2778 & 17156 & 25259 & 45192 \\
\hline
\end{tabular}

Whitehaven UD. Of these, $44 \%$ were underground workers, $6 \%$ surface workers, and $50 \%$ unspecified in this respect. All but 16 were followed up to the end of 1982 or to death or emigration whichever was the earlier. Details of the man-years at risk accumulated during the study period are shown in table 2 according to age group, whereas in table 3 the status of the study group at the end of the follow up period, December 1982 , is shown.

There were 1604 deaths between October 1939 and December 1982, of which 1521 occurred at ages below 85 . Table 4 shows the numbers of deaths below age 85 from major causes, together with the numbers expected if the study group had experienced a mortality similar to that of all men in England and Wales.

In the study group as a whole mortality from all causes was increased by over $20 \%$, mainly due to a $60 \%$ excess mortality from respiratory diseases, a 3.6fold increased mortality from tuberculosis, and a $50 \%$ excess mortality from accidents and violent causes. There was also a slight excess of deaths from circulatory diseases but no increased mortality from malignant disease. Among underground miners the excesses were more pronounced, being $50 \%$ for all causes combined, with cancer showing a $28 \%$ excess. Indeed all the major causes examined showed larger excesses among underground than among surface or unspecified mine workers.

Table 5 shows details of observed and expected numbers of specific cancers. In the whole group there was no excess of lung cancer but in underground workers there was a $21 \%$ excess. Of other major sites, stomach and colorectal cancer showed excesses of $25 \%$ in the whole group and among underground workers of $53 \%$ and $45 \%$, respectively.

Table 3 Status of subjects at end of study 31 December 1982

\begin{tabular}{lc}
\hline Living & 298 \\
Dead & $1604^{*}$ \\
Emigrated & 9 \\
Lost to follow up & 36 \\
Total & 1947 \\
\hline
\end{tabular}

${ }^{*}$ Of whom 1521 were aged under 85 at death. 
Table 4 Observed and expected numbers of deaths among iron mine workers from major causes 1939-82. (Expected numbers calculated using mortality rates from all men in England and Wales)

\begin{tabular}{|c|c|c|c|c|c|c|c|c|c|c|c|c|c|}
\hline \multirow[b]{2}{*}{ Disease } & \multirow[b]{2}{*}{$I C D$ code (8) } & \multicolumn{3}{|c|}{ Above } & \multicolumn{3}{|c|}{ Below } & \multicolumn{3}{|c|}{ Not stated } & \multicolumn{3}{|l|}{ Total } \\
\hline & & Obs & $\operatorname{Exp}$ & $O: E$ & Obs & $\operatorname{Exp}$ & $O: E$ & Obs & $\operatorname{Exp}$ & $O: E$ & Obs & $\operatorname{Exp}$ & $O: E$ \\
\hline $\begin{array}{l}\text { Tuberculosis } \\
\text { Neoplasms } \\
\text { Circulatory: } \\
\text { Ischaemic heart } \\
\text { Cerebrovascular } \\
\text { Respiratory } \\
\text { Gastrointestinal } \\
\text { Accidents, etc } \\
\text { Other causes }\end{array}$ & $\begin{array}{l}(010-012) \\
(140-239) \\
(390-458) \\
(410-414) \\
(430-438) \\
(460-519) \\
(520-577) \\
(800-999)\end{array}$ & $\begin{array}{r}1 \\
16 \\
37 \\
15 \\
9 \\
8 \\
7 \\
2 \\
8\end{array}$ & $\begin{array}{r}1 \cdot 43 \\
15 \cdot 79 \\
37 \cdot 71 \\
18 \cdot 36 \\
8 \cdot 75 \\
11 \cdot 23 \\
2 \cdot 24 \\
2 \cdot 40 \\
5 \cdot 54\end{array}$ & $\begin{array}{l}0 \cdot 70 \\
1.01 \\
0 \cdot 98 \\
0 \cdot 83 \\
1.03 \\
0 \cdot 71 \\
3 \cdot 13 \\
0 \cdot 83 \\
1.44\end{array}$ & $\begin{array}{r}51 \\
132 \\
327 \\
174 \\
71 \\
135 \\
19 \\
39 \\
55\end{array}$ & $\begin{array}{r}10 \cdot 73 \\
102 \cdot 94 \\
242 \cdot 97 \\
113 \cdot 33 \\
56 \cdot 61 \\
72 \cdot 27 \\
15 \cdot 19 \\
15 \cdot 89 \\
38 \cdot 29\end{array}$ & $\begin{array}{l}4.75 \\
1.28 \\
1.35 \\
1.54 \\
1.25 \\
1.87 \\
1.25 \\
2.45 \\
1.44\end{array}$ & $\begin{array}{r}36 \\
124 \\
305 \\
165 \\
53 \\
149 \\
16 \\
17 \\
37\end{array}$ & $\begin{array}{r}12 \cdot 64 \\
143 \cdot 06 \\
324 \cdot 15 \\
164 \cdot 25 \\
73 \cdot 12 \\
96 \cdot 66 \\
19 \cdot 36 \\
20 \cdot 89 \\
45 \cdot 77\end{array}$ & $\begin{array}{l}2.85 \\
0.87 \\
0.94 \\
1.01 \\
0.73 \\
1.54 \\
0.83 \\
0.81 \\
0.81\end{array}$ & $\begin{array}{c}88^{*} \\
272 \\
669 \\
354 \\
133 \\
292 \dagger \\
42 \\
58 \\
100\end{array}$ & $\begin{array}{r}24 \cdot 80 \\
261 \cdot 79 \\
604 \cdot 82 \\
295 \cdot 94 \\
138 \cdot 48 \\
180 \cdot 16 \\
36 \cdot 78 \\
39 \cdot 18 \\
89 \cdot 62\end{array}$ & $\begin{array}{l}3.55 \\
1.04 \\
1.11 \\
1.20 \\
0.96 \\
1.62 \\
1.14 \\
1.48 \\
1.12\end{array}$ \\
\hline All causes & $(001-999)$ & 79 & $76 \cdot 34$ & 1.04 & 758 & $498 \cdot 28$ & $1 \cdot 52$ & 684 & $662 \cdot 53$ & 1.03 & 1521 & $1237 \cdot 15$ & $1 \cdot 23$ \\
\hline
\end{tabular}

"Of which 46 were "silicotuberculosis" (ICD 10).

tOf which 41 were silicosis (ICD 5150).

Table 6 shows the numbers of deaths from major causes and from certain cancers with expected numbers calculated using mortality rates for social classes III and IV combined, the group to which miners are allocated by the Registrar General. In most cases the findings are similar to those in the previous analysis (table 5), though in the case of stomach cancer the excess is more pronounced (observed to expected ratio 1.39 compared with 1.24 ). An adjustment for social class would be expected to reduce, not increase, the SMR for stomach cancer. It should be noted, however, that the lower value refers to all ages (table 5) whereas the social class analysis refers only to men aged under 65. In fact the ratio for men of these ages of observed to expected numbers, using national stomach cancer mortality rates, is 1.54 , so that the above value of 1.39 does represent a reduction, when considering comparable age groups.

Table 7 shows the results of the corresponding analyses using death rates specific for urban and rural areas. With the exception of deaths from circulatory diseases and violent causes which were not appreciably altered, all the excesses became more pronounced when these new rates were used as the standard. Compared with men in similar mainly rural areas, iron mine workers had a $23 \%$ excess mortality from neoplasms (50\% in underground workers) and a twofold mortality from respiratory diseases $(2 \cdot 3$-fold in underground workers). The increased mortality from tuberculosis amounted to 7.6-fold (10.3-fold in underground workers) whereas for lung cancer there was a $30 \%$ excess $(50 \%$ among underground workers).

\section{DIFFERENT CALENDAR PERIODS}

The years 1948-67 were covered by Boyd and his colleagues and for this period analyses were carried out by both the man-years at risk and the proportionate methods. The results are summarised in table 8 . In the proportionate analysis factors were derived as in the Boyd study from mortality data from all rural districts of the country and from all urban areas with populations under 50000 (see Methods). The number of deaths analysed by the proportionate method is smaller than in the corresponding man-years analysis because the former was restricted to a subgroup of the

Table 5 Observed and expected numbers of deaths among iron mine workers from different cancers 1939-82. (Expected numbers calculated using mortality rates from all men in England and Wales)

\begin{tabular}{|c|c|c|c|c|c|c|c|c|c|c|c|c|c|}
\hline \multirow[b]{2}{*}{ Neoplasm } & \multirow[b]{2}{*}{ ICD code (8) } & \multicolumn{3}{|c|}{ Above } & \multicolumn{3}{|c|}{ Below } & \multicolumn{3}{|c|}{ Not stated } & \multicolumn{3}{|c|}{ Total } \\
\hline & & $O b s$ & Exp & $O: E$ & Ohs & Exp & $O: E$ & Obs & Exp & $O: E$ & Obs & Exp & $O: E$ \\
\hline Stomach & $(151)$ & 3 & $2 \cdot 36$ & $1 \cdot 27$ & 25 & $16 \cdot 34$ & $1 \cdot 53$ & 21 & $20 \cdot 75$ & 1.01 & 49 & $29 \cdot 46$ & $1 \cdot 24$ \\
\hline Colon & (153) & 1 & $1 \cdot 28$ & 0.78 & 11 & $8 \cdot 70$ & $1 \cdot 26$ & 13 & 10.99 & $1 \cdot 18$ & 25 & 20.97 & 1.19 \\
\hline Rectum & (154) & $i$ & 1.04 & 0.96 & 12 & $7 \cdot 19$ & 1.67 & 10 & 8.93 & $1 \cdot 12$ & 23 & $17 \cdot 16$ & $1 \cdot 34$ \\
\hline Pancreas & (157) & 1 & 0.63 & 1.58 & 5 & $4 \cdot 03$ & $1 \cdot 24$ & 6 & $5 \cdot 74$ & 1.05 & 12 & $10 \cdot 40$ & 1.15 \\
\hline Lung, bronchus & (162) & 4 & $5 \cdot 13$ & 0.78 & 39 & $32 \cdot 11$ & $1 \cdot 21$ & 41 & $49 \cdot 50$ & 0.82 & 84 & $86 \cdot 75$ & 0.97 \\
\hline Prostate & (185) & 0 & $1 \cdot 17$ & $0 \cdot 0$ & 7 & $7 \cdot 31$ & 0.96 & 5 & $9 \cdot 79$ & 0.51 & 12 & $18 \cdot 27$ & 0.66 \\
\hline Bladder & (188) & 2 & 0.67 & $2 \cdot 97$ & 5 & $4 \cdot 29$ & $1 \cdot 16$ & 7 & $5 \cdot 99$ & 1.17 & 14 & 10.96 & $1 \cdot 28$ \\
\hline Hodgkin`s disease & (201) & 0 & 0.09 & 0.0 & 0 & 0.60 & 0.0 & 0 & 0.86 & 0.0 & 0 & 1.55 & 0.0 \\
\hline Leukaemia & $(204-207)$ & 0 & 0.29 & $0 \cdot 0$ & 2 & 1.76 & $1 \cdot 14$ & 2 & $2 \cdot 63$ & 0.76 & 4 & 4.68 & 0.86 \\
\hline Other cancers & & 4 & $3 \cdot 13$ & $1 \cdot 28$ & 26 & $20 \cdot 61$ & $1 \cdot 26$ & 19 & $27 \cdot 88$ & 0.68 & 49 & $51 \cdot 59$ & 0.95 \\
\hline All cancers & $(140-239)$ & 16 & $15 \cdot 79$ & $1 \cdot 01$ & 132 & $102 \cdot 94$ & $1 \cdot 28$ & 124 & 143.06 & 0.87 & 272 & $261 \cdot 79$ & $1 \cdot 04$ \\
\hline
\end{tabular}


Table 6 Observed and expected numbers of deaths among iron mine workers aged under 65 from major causes $1939-82$. (Expected numbers based on mortality rates for social classes III and IV)

\begin{tabular}{|c|c|c|c|c|c|c|c|c|c|c|c|c|c|}
\hline \multirow[b]{2}{*}{ Disease } & \multirow[b]{2}{*}{ ICD code (8) } & \multicolumn{3}{|c|}{ Above } & \multicolumn{3}{|c|}{ Below } & \multicolumn{3}{|c|}{ Not stated } & \multicolumn{3}{|c|}{ Total } \\
\hline & & Obs & Exp & $O: E$ & $O b s$ & $\operatorname{Exp}$ & $O: E$ & Obs & $\operatorname{Exp}$ & $O: E$ & Obs & $\operatorname{Exp}$ & $O: E$ \\
\hline Tuberculosis & $(10-12)$ & 0 & 1.44 & - & 38 & $10 \cdot 39$ & $3 \cdot 66$ & 29 & $12 \cdot 92$ & $2 \cdot 25$ & 67 & $24 \cdot 74$ & $2 \cdot 71$ \\
\hline Neoplasms: & $(140-239)$ & 9 & $5 \cdot 77$ & $1 \cdot 56$ & 53 & 37.62 & 1.41 & 53 & $54 \cdot 25$ & 0.98 & 115 & 97.64 & $1 \cdot 18$ \\
\hline Stomach cancer & $(151)$ & 3 & 0.96 & $3 \cdot 14$ & 11 & $6 \cdot 76$ & 1.63 & 9 & $8 \cdot 84$ & $1 \cdot 02$ & 23 & $16 \cdot 56$ & $1 \cdot 39$ \\
\hline Lung cancer & $(162-163)$ & 1 & $2 \cdot 26$ & 0.44 & 18 & 14.03 & $1 \cdot 28$ & 17 & $22 \cdot 00$ & 0.77 & 36 & $38 \cdot 29$ & 0.94 \\
\hline Leukaemia & $(204-207)$ & 0 & 0.11 & $0 \cdot 00$ & 0 & 0.70 & 0.00 & 2 & 1.06 & 1.89 & 2 & 1.87 & 1.07 \\
\hline Ischaemic heart & $(410-414)$ & 5 & $5 \cdot 29$ & 0.95 & 55 & $32 \cdot 69$ & 1.68 & 44 & $50 \cdot 15$ & 0.88 & 104 & $88 \cdot 14$ & $1 \cdot 18$ \\
\hline Cerebrovascular & $(430-438)$ & 1 & $1 \cdot 59$ & 0.63 & 18 & $10 \cdot 89$ & 1.65 & 7 & 14.69 & 0.48 & 26 & $27 \cdot 16$ & 0.96 \\
\hline Respiratory & $(460-519)$ & 4 & $2 \cdot 90$ & $1 \cdot 38$ & 41 & $20 \cdot 29$ & $2 \cdot 02$ & 42 & $26 \cdot 96$ & 1.56 & 87 & $50 \cdot 16$ & 1.73 \\
\hline Gastrointestinal & $(520-577)$ & 3 & 0.76 & 3.97 & 12 & $5 \cdot 46$ & $2 \cdot 20$ & 3 & 6.93 & 0.43 & 18 & $13 \cdot 14$ & $1 \cdot 37$ \\
\hline Accidents, etc & $(800-999)$ & 1 & 1.33 & 0.75 & 30 & 8.68 & 3.46 & 10 & $12 \cdot 01$ & 0.83 & 41 & $22 \cdot 01$ & 1.86 \\
\hline Other causes & & 0 & $2 \cdot 60$ & 0.00 & 10 & $18 \cdot 56$ & 0.54 & 10 & 23.09 & 0.43 & 20 & $44 \cdot 27$ & 0.45 \\
\hline All causes & $(1-999)$ & 27 & $23 \cdot 69$ & $1 \cdot 14$ & 270 & $158 \cdot 54$ & $1 \cdot 70$ & 212 & 218.76 & 0.97 & 509 & 400.99 & $1 \cdot 27$ \\
\hline
\end{tabular}

latter-to those that occurred in Ennerdale RD and Whitehaven UD and in which the death certificate showed a mention of an iron mine occupation. Many men resident in the study area in 1939 and who later died had moved away from the study area or changed their occupation and such deaths were excluded from the proportionate analysis. The numbers in this proportionate analysis are smaller than in the Boyd study, no doubt because the present study is restricted to men resident in 1939 in the study area. Deaths in men who joined the industry after 1939 or returned to it having already joined the armed forces by October 1939 could not have been included in the present study but could have been eligible for inclusion in the Boyd study.

The data in table 8 show that for the "Boyd" period there is a fairly close measure of agreement between the excess of deaths from lung cancer in the present study using urban rural specific mortality rates, whether in the man-years $(59 \%)$ or the proportionate analyses $(55 \%)$, and the proportionate findings in the
Boyd study (46\%). The corresponding mortalities for respiratory diseases were closer, being $2 \cdot 3$-fold and $2 \cdot 4$-fold respectively in the present study compared with 2-3-fold in the Boyd study.

Comparisons have not been possible for underground and above ground workers between the Boyd and the present studies because we do not know the criteria used in the former study for categorising the substantial number of workers for whom such details were not stated on the death certificate.

Lung cancer data were also analysed using urban and rural specific mortality rates in the periods preceding (1939-47) and after (1968-82) that covered by table 8 . In 1939-47 the excess mortality was $26 \%$ (based on eight deaths) and in 1968-82 13\% (based on 26 deaths).

Of the 86 deaths attributed to silicosis or silicotuberculosis, 29 occurred between 1939 and 1946 and 57 between 1947 and 1966. No death from these causes was recorded after 1966. No subject in the study had his death attributed to "pulmonary siderosis."

Table 7 Observed and expected numbers of deaths from major causes and for certain malignancies. (Expected numbers calculated using urban and rural area specific mortality rates)

\begin{tabular}{|c|c|c|c|c|c|c|c|c|c|c|c|c|}
\hline \multirow[b]{2}{*}{ Disease } & \multicolumn{3}{|c|}{ Above ground } & \multicolumn{3}{|c|}{ Below' ground } & \multicolumn{3}{|c|}{ Not specified } & \multicolumn{3}{|l|}{ Total } \\
\hline & Obs & Exp & $O: E$ & Obs & Exp & $O: E$ & Obs & Exp & $O: E$ & Ohs & Exp & $O: E$ \\
\hline $\begin{array}{l}\text { Respiratory } \\
\text { Gastrointestinal } \\
\text { Accidents } \\
\text { Other causes }\end{array}$ & $\begin{array}{l}8 \\
7 \\
2 \\
8\end{array}$ & $\begin{array}{l}9 \cdot 47 \\
1 \cdot 59 \\
2 \cdot 47 \\
5 \cdot 83\end{array}$ & $\begin{array}{l}0.84 \\
4.40 \\
0.81 \\
1.37\end{array}$ & $\begin{array}{r}135 \\
19 \\
39 \\
55\end{array}$ & $\begin{array}{l}59 \cdot 45 \\
10 \cdot 89 \\
15 \cdot 76 \\
39 \cdot 32\end{array}$ & $\begin{array}{l}2 \cdot 27 \\
1 \cdot 74 \\
2 \cdot 48 \\
1 \cdot 40\end{array}$ & $\begin{array}{r}149 \\
16 \\
17 \\
37\end{array}$ & $\begin{array}{l}81 \cdot 06 \\
13.62 \\
21 \cdot 72 \\
49 \cdot 09\end{array}$ & $\begin{array}{l}1.84 \\
1 \cdot 18 \\
0 \cdot 78 \\
0.75\end{array}$ & $\begin{array}{r}292 \\
42 \\
58 \\
100\end{array}$ & $\begin{array}{r}149 \cdot 98 \\
26 \cdot 10 \\
39 \cdot 95 \\
94 \cdot 23\end{array}$ & $\begin{array}{l}1.95 \\
1.61 \\
1.45 \\
1.06\end{array}$ \\
\hline All causes & 79 & $72 \cdot 26$ & 1.09 & 758 & $467 \cdot 36$ & $1 \cdot 62$ & 684 & $619 \cdot 96$ & $1 \cdot 10$ & 1521 & $1159 \cdot 58$ & $1 \cdot 31$ \\
\hline
\end{tabular}


Table 8 Observed to expected ratios of deaths obtained using proportionate and prospective methods of analysis and using different mortality rates to derive expected values. (Observed numbers of deaths in parentheses) (1948-67)

\begin{tabular}{|c|c|c|c|c|c|}
\hline \multirow[b]{2}{*}{ Disease } & \multicolumn{3}{|c|}{$\begin{array}{l}\text { Prospective analysis } \\
\text { Using mortality rates for: }\end{array}$} & \multirow{2}{*}{\multicolumn{2}{|c|}{$\begin{array}{l}\text { Proportionate analyses } \\
\text { Present study } \quad \quad \text { Boyd study } \dagger\end{array}$}} \\
\hline & Whole country & Social classe & *Urban/rural & & \\
\hline $\begin{array}{l}\text { Lung cancer } \\
\text { Other cancers } \\
\text { Respiratory and tuberculosis }\end{array}$ & $\begin{array}{l}1.13(50) \\
1.45(104) \\
1.78(180)_{\ddagger}^{\ddagger}\end{array}$ & $\begin{array}{l}1 \cdot 26(28) \\
1 \cdot 19(35) \\
2 \cdot 13(73)\end{array}$ & $\begin{array}{l}1.59(50) \\
1 \cdot 22(104) \\
2 \cdot 32(180) \ddagger\end{array}$ & $\begin{array}{l}1 \cdot 55(30) \\
1 \cdot 13(61) \\
2 \cdot 44(131)\end{array}$ & $\begin{array}{l}1.46(42) \\
0.98(74) \\
2 \cdot 30(174)\end{array}$ \\
\hline
\end{tabular}

*Ages up to 65 only.

+Deaths in Ennerdale and Whitehaven only with mention of iron ore on death certificate.

†Of which 57 were attributed to silicosis or silicotuberculosis.

\section{Discussion}

This prospective study of a cohort of iron mine workers confirms the excess of lung cancer found in an earlier study using a different method.' This excess was evident, however, only by comparison with the mortality of men living in similar (mainly rural) areas and no significant excess was found when either all men or men of similar social class in England and Wales were used as the standard. The choice of standard is therefore crucial. It is unusual for mines to exist in so rural an area as West Cumbria, so if the miners in this study originated mainly from urban areas it could be argued that the appropriate standard should be men living in urban areas. We have taken the opportunity of examining data on place of birth, which since 1968 has been recorded at death registration. More than $90 \%$ of men in this study who died after 1968 were born in rural Cumbria, an observation which supports the use of rural area specific mortality data as the standard.

The excess mentioned above depends not only on the standard used for comparison but also on using the same calendar period as in the previous study by Boyd and his colleagues-namely, 1948-67. Indeed, in the succeeding period, 1968-82, the excess of lung cancer had largely disappeared (O:E ratio $1 \cdot 13)$. An increased incidence of lung cancer among iron ore miners has also been noted in Sweden ${ }^{23}$ and has been related to the high levels of radon recorded in the mines both in Cumbria ${ }^{45}$ and in Sweden. ${ }^{26}$ This would accord with the excess of lung cancer recorded after other exposures to high radon levels, such as among fluorspar miners of Newfoundland, ${ }^{7}$ tin miners in Cornwall, ${ }^{8}$ and the much studied uranium miners in Colorado. ${ }^{9}$ It is not known, however, if this is the entire explanation or whether the inhalation of iron oxide or silicon or a combination of these factors with radon is involved. ${ }^{10}$ It has recently been reported that haematite miners in Minnesota who are exposed only to low levels of radon do not have an increased mortality from lung cancer." This evidence is consistent with the radon hypothesis, but it should be noted that the mines in question have been subject to an energetic control programme that would lower exposure both to silica and to iron oxide.

The decline recorded in this study in the excess of lung cancer after 1967 is consistent with any of the theories mentioned above. Serial measurements of levels of silica or iron oxide in the mines are not available to us, though radon levels in all the mines were surveyed in 1969, three of them again in 1970. The highest radon levels recorded in 1969 were in a mine in the study area that closed in that year, and these ranged from 0.35 to $3.2 \mathrm{WLs}$ (median 2.0 ). The ranges in the other three mines were $0.3-1.0$ (median 0.5 ), 0.3-0.8 (median 0.6), 0.3-0.8 (median 0.6), and $0 \cdot 15-0 \cdot 2$ (median 0.15) WLs. In 1973 the levels in the same mines (though not identified to allow individual comparisons) were $0.005-0.3$ (mean 0.02 ), $0 \cdot 1-0.2$ (mean 0.6), and 0.3-0.85 (mean 0.6) WLs. ${ }^{45}$

Despite the absence of satisfactory serial measurements of any of the possible causative agents, the reduction in lung cancer mortality clearly cannot be attributed simply to improvements in dust control and in the ventilation of the mines after 1967. The fact that before 1968 men showed a significant excess of lung cancer in postretirement age groups indicates that leaving the mines is not of itself sufficient to remove most of the excess risk of lung cancer. Many men stopped working in the mines before the usual retirement age after 1967 . Indeed, in only $40 \%$ of the deaths after 1967 was an iron mining occupation mentioned as being the last full time job. Moreover, only about half the man-years at risk after 1967 were contributed by men below the usual retirement age (65). The proportion of the man-years after 1967 that were spent exposed to underground work is likely, therefore, to have been relatively low, and perhaps less than a quarter of the total. Thus although the fall in lung cancer mortality after 1967 recorded in this study is consistent with reduced exposure to radon, silica, or iron oxide in the underground air, this must partly have been occasioned by men changing their occupation. Indeed, this must have occurred for many men 
when the largest mine in the area (which also had the highest radon levels recorded in any British haematite mine in 1969) closed in 1969. The absence of an appreciable excess after 1968 is probably due to extinction of the group of men with long durations of exposure to the underground air in periods before improvements in ventilation, begun in 1935 , became significant. ${ }^{12}$

In view of the resurgence of interest in silica as a cause of lung cancer, it is noteworthy that between 1968 and 1982 when mortality from lung cancer was close to "average" for the general population, mortality from silicosis and silicotuberculosis had also fallen to average levels - namely zero-annual age adjusted rates having been 117 between 1939 and 1947 and 111 per 100000 between 1948 and 1967.

\section{References}

1 Boyd JT, Doll R, Faulds JS, Leiper J. Cancer of the lung in iron ore (haematite) miners. Br J Ind Med 1970;27:97-105.

2 Jorgensén HS. A study of mortality from lung cancer among 126-33.

3 Renard KGSC. Respiratory cancer mortality in an iron ore mine in northern Sweden. Ambio 1974;2:67-9.

4 Duggan MJ, Soilleux PJ, Strong JC, Howell DM. The exposure of United Kingdom miners to radon. BrJ Ind Med 1970;27:106-9.

5 Strong JC, Laidlow AJ, O'Riordan MC. Radon and its daughters in various British mines. (NRPB-R39.) Aldermaston: National Radiation Protection Board, 1975.

6 Radford EP, Renard KGSC. Lung cancer in Swedish iron miners exposed to low doses of radon daughters. $N$ Eng $J$ Med 1984;310:1485-94.

7 de Villiers AJ, Windish JP. Lung cancer in a fluorspar mining community. 1. Radiation, dust and mortality experience. $\mathrm{Br} J$ Ind Med 1964;21:94-109.

8 Fox AJ, Goldblatt P, Kinlen LJ. A study of the mortality of Cornish tin miners. Br J Ind Med 1981;38:378-80.

9 Wagoner JK, Lundin FE, Holaday DA, Lloyd JW. Radiation as the cause of lung cancer among uranium miners. $N$ Engl J Med 1965;273:181-8.

10 International Agency for Research on Cancer. Monographs on the evaluation of the carcinogenic risk of chemicals to humans. Suppl 4. Lyon: IARC, 1982.

11 Lawler AB, Mandel JS, Schuman LM, Lubin JH. A retrospective cohort mortality study of iron ore (hematite) miners in Minnesota. J Occup Med 1975;27:507-17.

12 Craw J. Pneumonoconiosis in the haematitie iron ore miners of West Cumbria: study of 45 years of control. J Soc Occup Med 1982;32:53-65.

\section{Destruction of manuscripts}

From I July 1985 articles submitted for publication will not be returned. Authors whose papers are rejected will be advised of the decision and the manuscripts will be kept under security for three months to deal with any inquiries and then destroyed. 